\title{
Attend to it now or lose it forever: Selective attention, metacontrast masking, and object substitution
}

\author{
MATTHEW S. TATA \\ University of British Columbia, Vancouver, British Columbia, Canada
}

\begin{abstract}
Metacontrast masking occurs when the visibility of a brief target stimulus is decreased by the subsequent appearance of another nearby visual stimulus. Early explanations of the phenomenon involved low-level mechanisms, but subsequent studies have suggested a role for selective attention. The results of three experiments presented here extend previous findings to the metacontrast paradigm. It is shown that the strength of metacontrast masking increases with the number of distractor items in a display, decreases when the targetlocation is validly but not invalidly precued, and is eliminated when search for the target is efficient (pop-out search) but not when search is inefficient (serial search). A connection between metacontrast masking and object substitution masking is considered.
\end{abstract}

The visibility of a brief visual target can be reduced by the presentation of a temporally lagging mask whose contours do not overlap those of the target. This type of backward masking is known as metacontrast masking (for a thorough review, see Breitmeyer, 1984). Research into metacontrast masking has focused on the spatial and temporal parameters of the stimuli, and theoretical explanations have been based on inhibitory contour interactions in low-level vision (Breitmeyer \& Ganz, 1976; Weisstein, Ozog, \& Szoc, 1975). A prototypical model based on contour interaction is the interchannel inhibition model proposed by Breitmeyer and Ganz. This model postulates two interacting channels carrying visual information: a transient channel that rapidly conveys information about the onsets and offsets of visual events, and a sustained channel that more slowly conveys information about other stimulus attributes, such as form and color. When the mask follows the target by about 50 $100 \mathrm{msec}$, activity in the transient channel triggered by the onset of the mask catches up to and inhibits activity in the slower sustained channel, which contains a representation of the contours of the target. This inhibition is thought to be responsible for the reduced visibility of the target.

Contour interaction schemes such as the interchannel inhibition model are based on the dynamic physiological

The author thanks Deborah Giaschi and Vince Di Lollo for their supervision throughoutthis study and Lawrence Ward and Robert Dougherty for helpful discussion in preparation of the manuscript. This work was done in partial fulfillment of the MSc degree to the author under the supervision of D. Giaschi. Funding was provided by NSERC Grant OGPO194526 to D. Giaschi and NSERC Grant OGP0006592 to V. Di Lollo. Correspondence should be addressed to M. S. Tata, Department of Psychology, University of British Columbia, 2136 West Mall, Vancouver, BC, V6T 1Z4 Canada (e-mail: mstata@interchange.ubc.ca). characteristics of visual neurons representing adjacent regions of space. The inhibitory mechanism underlying metacontrast masking in these models is thought to act over small distances (less than about $1^{\circ}$ of visual angle) and within a brief window of time (a few tens of milliseconds). Conceptualized as a local phenomenon occurring early in the visual system, metacontrast masking should be affected minimally, if at all, by stimuli that are presented at locations far removed from the target and the mask. The results of several studies, however, suggest that the increase in the overall complexity of the display by the addition of distractor items leads to stronger metacontrast masking (Averbach \& Coriell, 1961), as well as to other related types of backward masking (Enns \& Di Lollo, 1997; Spencer \& Shuntich, 1970). These findings suggest that low-level contour interaction models might not provide a complete picture of the metacontrast masking phenomenon.

The earliest indication that the mechanisms underlying metacontrast masking involve more than a low-level inhibitory contour interaction between the contours of the mask and those of the target came from a set-size effect reported by Averbach and Coriell (1961) in an investigation of iconic memory. In that study, a target letter was singled out from a briefly presented array of letters by the subsequent appearance of a ring probe, centered at the same location as the target's, but slightly larger than the target in diameter. Accuracy of target identification depended on the delay between the onset of the target and the onset of the ring (stimulus onset asynchrony, SOA). When the target and ring appeared simultaneously, accuracy was well above chance. Accuracy fell dramatically at SOAs of around $100 \mathrm{msec}$, but rebounded with SOAs longer than $100 \mathrm{msec}$. This U-shaped function relating accuracy to SOA is characteristic of metacontrast masking (Breitmeyer \& Ganz, 1976). Im- 
portantly, when the display consists of a single letter followed by a ring probe, accuracy is uniformly high at all SOAs. The U-shaped function emerges only when the target appears among several distractor letters. Averbach and Coriell interpreted this finding in terms of capacity limitations in iconic memory (but see Eriksen \& Rohrbaugh, 1970b, for a different interpretation); however, this finding is significant in the context of metacontrast masking. It indicates that the presence of stimuli far removed from the target and mask contributes to the overall masking effect, thus suggesting that metacontrast is not exclusively a low-level peripheral process. This notion has been further supported by studies of related types of backward masking that have demonstrated less pronounced masking of word targets than nonword targets (Michaels \& Turvey, 1979), and greater masking when target and mask are of the same geometric shape than when they are of different shapes (Uttal, 1970).

Stronger metacontrast masking in complex displays might be explained by recasting metacontrast and related types of backward masking into the context of visual selective attention (Breitmeyer \& Ganz, 1976; Enns \& Di Lollo, 1997). According to this account, the addition of distractors to a display prevents immediate focusing of attention on the target. This occurs because the target cannot be found in the display until it is singled out from the distractors by the subsequent appearance of the mask. The hypothesis that underlies this account is that the strength of metacontrast masking depends on whether the observer has focused attention on the target before the onset of the mask. The visual representation of an unattended target might be impoverished to the extent that even a weak mask renders it insufficient to support perception. Alternatively, focused attention might consolidate the representation of the target, preventing suppression by the mask.

Several recent studies have suggested that attention might be a factor in metacontrast masking. Ramachandran and Cobb (1995) reported a series of experiments in which they instructed observers to perceptually group the target with items elsewhere in the display, a task that presumably involves focusing attention on the target. This manipulation reduces the strength of metacontrast masking. Enns and Di Lollo (1997) showed that a mask with minimal contours (four dots describing a notional square surrounding the target) can exert strong backward masking when a complex display creates uncertainty as to target location. Both of these studies suggest that metacontrast masking might be modulated by the attentional state of the observer. Shelley-Tremblay and Mack (1999) explored this notion further by using stimuli known to be resistant to inattentional blindness. Inattentional blindness is the inability to perceive a stimulus that has not been selectively attended. Highly salient or meaningful stimuli, such as the observer's name, are resistant to inattentional blindness, presumably because they automatically capture attention. Shelley-Tremblay and Mack found that a metacontrast mask is less effec- tive when the target is resistant to inattentional blindness relative to control targets. This further suggests a role for selective attention in determining the strength of metacontrast masking.

Of particular relevance to this discussion of metacontrast masking is a recent investigation of a type of masking known as object substitution (Di Lollo, Enns, \& Rensink, 2000). That study clearly demonstrated that common attentional manipulations such as set size, spatial cuing, and target pop-out have dramatic effects on this type of backward masking. In that study, however, the authors sought to differentiate object substitution from metacontrast masking by using a common-onset paradigm (see Di Lollo, Bischof, \& Dixon, 1993), in which the target and mask have simultaneous onset times but different offset times (i.e., there is no SOA). In that paradigm, masking is found to increase as the mask outlives the target by an increasing duration. The authors' account for their finding, to be discussed further below, centers on a theoretical description of the neural processes occurring during the prolonged presentation of the mask. As such, neither their results nor their theoretical account applies directly to the metacontrast paradigm, in which the target and mask are presented for precisely the same duration. Due to fundamental differences in the temporal dynamics of these two paradigms, it remains unclear how the attentional manipulations employed by Di Lollo et al. (2000) might influence the strength or time course of metacontrast masking.

The role of attention in metacontrast masking remains unclear. Ramachandran and Cobb (1995) and ShelleyTremblay and Mack (1999) provided only indirect evidence that metacontrast masking is weaker when attention is focused on the target. Ramachandran and Cobb did not manipulate selective attention directly, and Shelley-Tremblay and Mack demonstrated only a correlation between resistance to inattentional blindness and resistance to metacontrast masking. Averbach and Coriell (1961) and Enns and Di Lollo (1997) reported preliminary evidence that display complexity influences backward masking, but neither study explored that possibility parametrically by evaluating masking at various levels of display complexity. These previous studies do, however, suggest an intriguing possibility: The profound influence of attention in common-onset masking demonstrated by Di Lollo et al. (2000) might apply to metacontrast masking as well. The present study provides a systematic exploration of the role of attention as a factor in metacontrast masking, and is motivated in part by the need to extend Di Lollo et al.'s (2000) findings beyond masking by common onset.

The approach taken in the present study was to examine metacontrast masking by directly manipulating the probability of attention's being focused on the target before the onset of the mask. One strategy, employed by Ramachandran and Cobb (1995) and Shelley-Tremblay and Mack (1999), is to make an otherwise strong metacontrast mask less effective by focusing attention on the 
target. The complementary strategy is to demonstrate that an otherwise weak metacontrast mask is made stronger when attention is not focused on the target. In the present study, both strategies are employed by using three common attentional manipulations: set size, spatial cuing, and target pop-out. The increase in the set size in a display is thought to delay the deployment of attention to the target by requiring a slow serial searching process. The present hypothesis is that this manipulation, by delaying attentional selection of the target, will strengthen an otherwise ineffective mask. In contrast, validly cuing the location of the target in advance (spatial precuing) or speeding search for the target by making it distinct from the distractors (target pop-out) should negate any setsize effect by allowing rapid attentional selection of the target (see Posner \& Cohen, 1984, for discussion of spatial cuing, and Eriksen \& Rohrbaugh, 1970a; Treisman \& Gelade, 1980; and Wolfe, Cave, \& Franzel, 1989, for discussions of set-size effects and target pop-out). If it can be demonstrated that the effectiveness of a metacontrast mask can be increased or decreased purely by manipulating attention, and without physical changes being made to the target and mask stimuli, it would confirm that metacontrast masking involves attentional mechanisms and is probably not mediated solely by local low-level inhibition.

\section{EXPERIMENT 1 \\ Increasing Display Complexity Leads to Increased Metacontrast Masking}

The first step in exploring the role of attention in metacontrast masking is to confirm that metacontrast is stronger when the target appears among distractors, as has been suggested in previous reports (Averbach \& Coriell, 1961; Enns \& Di Lollo, 1997). The purpose of the following experiment was to substantiate these reports by evaluating metacontrast masking over a wider range of set sizes. The approach taken here was to demonstrate that a mask that produces little or no metacontrast masking in a single-item display can produce strong masking when the target appears in a more complex display.

\section{Method}

Four observers with normal or corrected-to-normal vision viewed a display consisting of two frames. The display was presented on a Tektronix 608 oscilloscope equipped with P15 phosphor and a fast plotting buffer (Finley, 1985). Front illumination of the screen was provided by two fluorescent lamps, attenuated to $10 \mathrm{~cd} / \mathrm{m}^{2}$ by neutral density filters placed over each lamp. Luminance of the screen and stimuli was calibrated with a Minolta LS 100 photometer.

The first frame in the display sequence contained 1, 2, 4, or 8 incomplete rings (similar to Landolt Cs) arranged randomly on a notional circle with $2^{\circ}$ radius around a central fixation point (Figure 1). The luminance of these $\mathrm{Cs}$ was $100 \mathrm{~cd} / \mathrm{m}^{2}$, and the frame was presented for $10 \mathrm{msec}$. The Cs were randomly oriented up, down, left, or right. One of the Cs was singled out as the target by a radial line extending from fixation. The target appeared at every possible location an equal number of times within a block and never appeared at the same location on successive trials. The observer's task was to report the orientation of this target. The second frame contained a ring that was concentric with the target and that served as a mask. The luminance of the mask was equal to that of the target in order to preclude the influence of other types of masking (see Breitmeyer, 1984). The mask was displayed for $10 \mathrm{msec}$ and appeared at an SOA of $0,40,80,120,160$, or 320 msec. Each observer was tested on each of 4 (set sizes) $\times 7$ (SOAs) conditions. Trials were blocked within conditions with 48 trials in each block. Each block was re-

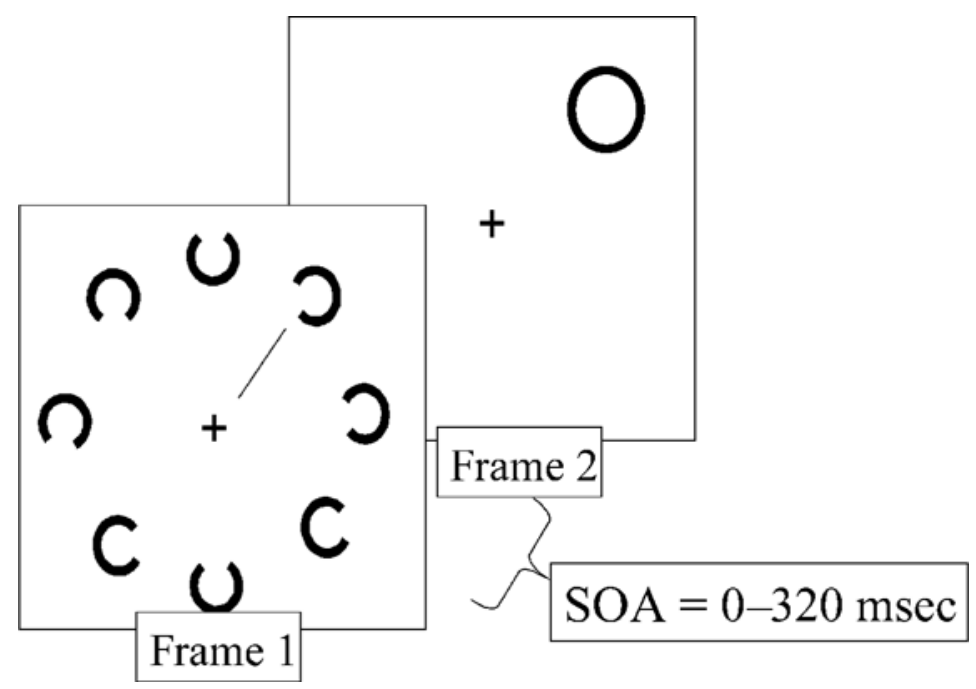

Figure 1. Schematic of the stimulus used in Experiment 1. Frame 1 contained $1,2,4$, or $8 \mathrm{Cs}$, one of which was singled out as the target by a radial line. The task was to discriminate the orientation of the target $\mathrm{C}$. A masking ring slightly larger than the target appeared at the target location in Frame 2 after a stimulus onset asynchrony (SOA) of 0-320 msec. 


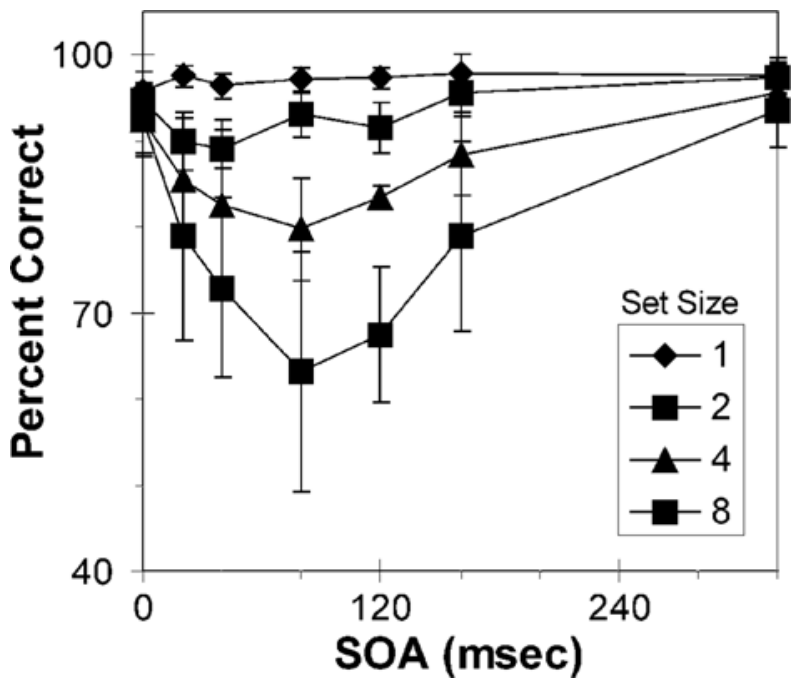

Figure 2. Results of Experiment 1 averaged across 4 observers. Accuracy in discriminating the orientation of the target, plotted as a function of stimulus onset asynchrony (SOA) for four different set sizes. Error bars represent the $95 \%$ confidence interval.

peated four times, yielding 192 trials per datapoint for each observer. Each $\mathrm{C}$ in the display was $47^{\prime}$ of arc in diameter, and the mask was $56^{\prime}$ in diameter, yielding a target-mask contour spacing of $4.5 \mathrm{~min}$. This target-mask spacing was chosen because it yielded little or no masking across all SOAs when set size was equal to 1 .

\section{Results}

The masking function (accuracy of discriminating the orientation of the target as a function of SOA) averaged over 4 observers is shown in Figure 2. Typical of metacontrast results, performance was near perfect when target and mask appeared simultaneously $(\mathrm{SOA}=0)$. Performance was also virtually identical for all set sizes at 0 SOA. In the set size 1 condition (i.e., when the target was presented alone), the masking function was flat and accuracy was near perfect across all SOAs. Performance in the set size 2 condition suffered only slightly at SOAs between 40 and $120 \mathrm{msec}$. By contrast, with set sizes of 4 and 8, a deep U-shaped masking function emerged. Maximal masking occurred with a set size of 8 at an SOA of $80 \mathrm{msec}$. Masking in the set size 8 condition was also effective at longer SOAs, relative to the smaller set sizes. Also typical of metacontrast masking functions, accuracy returned to nearly $100 \%$ with a sufficiently long SOA, regardless of set size. A within-subjects analysis of variance (ANOVA) revealed significant effects of set size $\left[F(3,9)=19.09, M S_{\mathrm{e}}=99.96, p<.001\right]$ and SOA $\left[F(6,18)=15.693, M S_{\mathrm{e}}=28.24, p<.001\right]$. The dependency of metacontrast masking on the number of items in the display was indicated by a significant interaction between set size and SOA $[F(18,54)=6.725$, $\left.M S_{\mathrm{e}}=17.31, p<.001\right]$.

\section{Discussion}

The results of Experiment 1 lend support to the notion that metacontrast masking involves processes other than, or in addition to, low-level inhibitory interactions between contours. The presence of distractor items at relatively distant locations in the display led to stronger metacontrast masking.

The set-size effect shown here can be interpreted in the context of an attentional hypothesis of metacontrast masking. The relationship between the time required to search for and find a target among distractors and the number and characteristics of those distractors has received considerable scrutiny in the attentional literature. The simplest visual search paradigm requires that observers find a target that differs from other items in the display by at least one feature (i.e., color, orientation, brightness, etc.). A common finding relevant to the present experiment is that visual search for a target increases linearly with the number of distractors when the distractors bear close resemblance to the target (as if the stimulus array were searched through one item at a time). This conceptualizationlends itself, in principle, to the interpretation of the set-size effect seen here. As set size increased, the observers were slowed in their efforts to locate and selectively attend to the target $\mathrm{C}$. The representation of the target was thus held up at a stage in which it was unattended and was vulnerable to the effects of the mask. In this view, the increase in masking strength with the increase in set size reflects a decrease in the probability that, on any individual trial, the observer had selectively attended the target before onset of the mask.

The present experiment differs from the classical visual search paradigm in that the target was identical to the distractors; the only difference was the presence of the radial line probe and the subsequent appearance of the mask at the same location. Thus the concept of visual search does not apply here in precisely the same sense that it applies in the interpretation of conventional visual search paradigms. The observers could not have searched through each item in a serial fashion. It is more likely that the observers' efforts to use the radial line as a cue were slowed by the presence of distractor items simply because of the added complexity of the display (Eriksen \& Rohrbaugh, 1970a). The interpretation, however, remains the same: The increase in set size led to a delay in selectively attending the target, thus leaving the target vulnerable to masking.

The general principle that emerges from this interpretation of Experiment 1 is that metacontrast masking is significantly modulated by selective attention. For identical targets and masks, metacontrast masking is stronger when the target is likely to be unattended at the time the mask appears.

Before continuing, two alternative hypotheses should be ruled out. First, it is unlikely that the increase in masking with larger set sizes arose from a crowding effect, an increase in lateral masking that is due to the distractors. Second, it might be concluded that the decreases in target visibility with increasing set sizes simply reflects a general decrement in perceptual ability in the absence of focused attention, as has been found in many investigations in which brief presentations of complex displays 


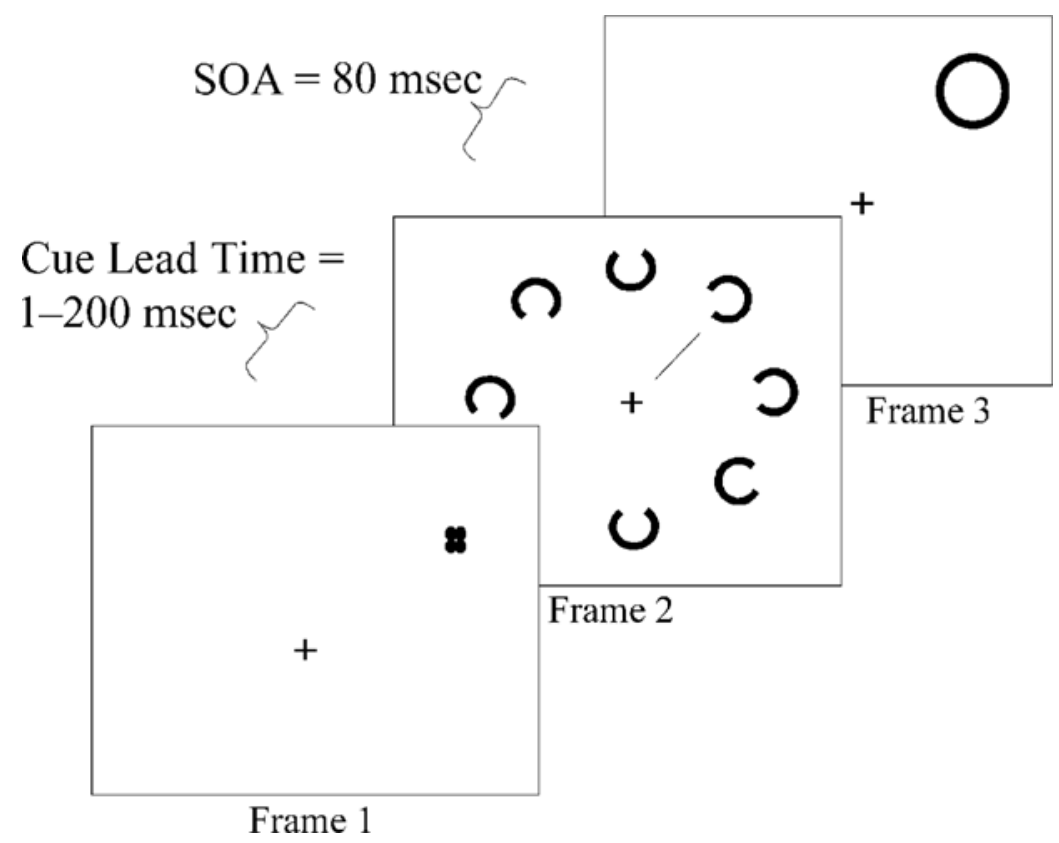

Figure 3. Schematic of the stimulus used in Experiment 2. A cluster of four dots appeared in Frame 1 and served as a spatial cue. This cue preceded Frame 2 by a lead time ranging from 1 to $200 \mathrm{msec}$. Frames 2 and 3 were the same as Frames 1 and 2, respectively, in Experiment 1, with set size and stimulus onset asynchrony (SOA) fixed at 8 and $80 \mathrm{msec}$, respectively. The cue correctly indicated the target location on $12 \%$ of trials.

have been used (e.g., Eriksen \& Rohrbaugh, 1970a). It is true that an increase in display complexity alone yielded a small systematic decrement in the visibility of the target. This can be seen by comparing accuracy across set sizes at $\mathrm{SOA}=1$. However, whether due to a crowding effect or to inattention, this small decrement in visibility cannot account for the large differences in accuracy across set sizes for intermediate SOAs. Selective attention and masking processes interact. With unfocused (but not with focused) attention, the appearance of the mask causes a loss of information about the target and, because the target has vanished from the display, this information cannot be recovered. The question as to why attention should interact with masking processes is taken up below.

The attentional hypothesis proposed here leads to two predictions. First, increased mask efficacy should be reduced or eliminated when attention is successfully focused on the target location prior to the appearance of the target display (by means of a spatial cue). Likewise, manipulations that facilitate rapid localization of the target should also reduce or eliminate masking by reducing the likelihood that the mask has appeared before attention could be focused on the target. These predictions were tested in Experiments 2 and 3.

\section{EXPERIMENT 2}

\section{Masking Is Reduced by an Attentional Precue}

The objective of Experiments 2 and 3 was to reduce or eliminate the set-size effect demonstrated in Experi- ment 1 by increasing the likelihood that the target could be selectively attended prior to the onset of the mask. This was accomplished by providing the observer with attentional cues to the target location. In Experiment 2, a cluster of dots, which appeared in advance of the target, served as a cue to direct the observer's attention either to the target location (if the cue was valid) or to the location of a distractor (if the cue was invalid). The primary goal of Experiment 2 was to test the following general hypothesis: If metacontrast masking is stronger at unattended locations, a valid cue should reduce masking, and an invalid cue should strengthen masking.

Also of interest is the nature of any shift of attention that might modulate metacontrast masking. Di Lollo et al. (2000) showed that a $100 \%$ valid cue could significantly reduce the degree of masking in the commononset paradigm. Likewise, Breitmeyer, Brown, Carter, and Havig (2000) reported that an $80 \%$ valid cue led to less masking on validly cued trials and to stronger masking on invalidly cued trials. Attention can be deployed to a spatial location either voluntarily, according to the goal or strategy of the observer, or involuntarily, as a reflexive response to salient events in the visual scene. Informative cues (cues that reliably predict the target location on most or all trials) presumably lead observers to voluntarily deploy their attention to the cued location, whereas noninformative cues (cues that do not reliably predict the target location) likely cause only reflexive orienting of attention. Despite the differences in the time course and consequences of these two modes of atten- 


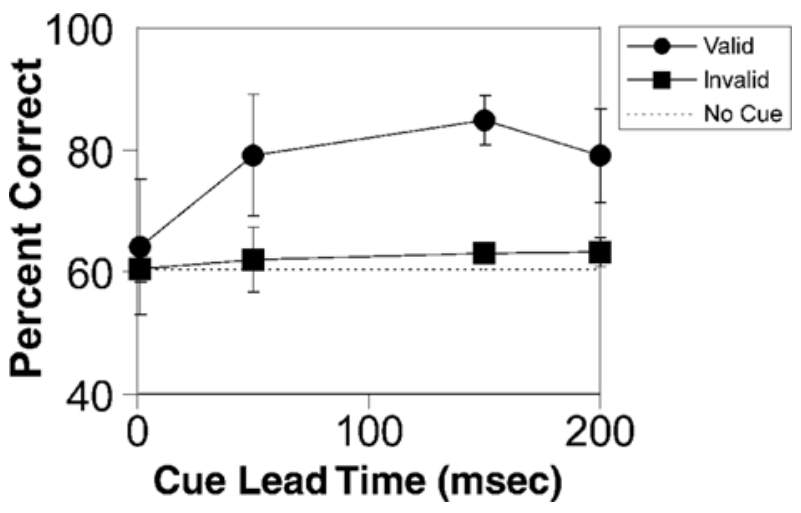

Figure 4. Results of Experiment 2 averaged across 3 observers. Accuracy in discriminating the orientation of the target, as a function of cue lead time for valid and invalid cues. The dotted line indicates average performance on the corresponding set size and stimulus onset asynchrony (SOA) condition from Experiment 1 , in which no cue appeared. Error bars represent the $95 \%$ confidence interval.

tion, no study has yet shown that reflexive orienting of attention is sufficient to modulate the strength of masking. A secondary goal of this experiment was to determine whether reflexive shifts of attention act to modulate the strength and time course of metacontrast masking in a manner similar to that of voluntary shifts. The cue in Experiment 2 validly predicted the target on only $12 \%$ of trials, so the observer had no incentive to actively use the cue. Finally, attention can be shifted with different speeds, depending on the nature of the stimulus (Nakayama \& Mackeben, 1989). A range of cue-target intervals was tested in order to obtain an indication of the time course of the effect of the cue on metacontrast masking.

\section{Method}

Three of the 4 observers who participated in Experiment 1 also served as observers in Experiment 2. The stimulus displays in Experiment 2 were similar to those in Experiment 1, except that a spatial cue was provided $1,50,150$, or $200 \mathrm{msec}$ prior to the onset of the target and distractors. The cue consisted of a square arrangement of four small dots clustered together at a point that subsequently became the center of a $\mathrm{C}$ in the target frame (Figure 3 ). The luminance of the cue was $200 \mathrm{~cd} / \mathrm{m}^{2}$, and it was presented for $1 \mathrm{msec}$. Subjectively, the cue appeared to be a small flash of light at one of the possible target locations. The cue validly indicated the location of the target on $12 \%$ of the trials and indicated the location of a distractor on all other trials. This yielded a 2 (validity) $\times 4$ (cue lead time) experimental design, carried out in blocks of 96 trials each. Set size and SOA were fixed at eight items and $80 \mathrm{msec}$, respectively, since these values produced maximal masking in Experiment 1. As in Experiment 1, the observer's task was to report the orientation of the target $\mathrm{C}$.

\section{Results}

Average accuracy for the orientation discrimination task for 3 observers is shown in Figure 4. As expected, masking was found to be reduced when a valid cue preceded the target by at least $50 \mathrm{msec}$. The difference in masking between validly and invalidly cued trials became more pronounced as the cue lead time was increased. A within-subjects ANOVA revealed a significant main effect of cue validity $\left[F(1,2)=26.10, M S_{\mathrm{e}}=\right.$ $48.89, p=.04]$, a significant main effect of cue lead time $\left[F(3,6)=6.03, M S_{\mathrm{e}}=25.17, p=.03\right]$, and a significant interaction between cue lead time and cue validity $\left[F(3,6)=4.70, M S_{\mathrm{e}}=18.89, p=.05\right]$.

The horizontal line plotted in Figure 4 represents performance in Experiment 1 with the same set size and SOA but without a cue. It is evident that no systematic reduction in performance resulted from an invalid cue.

\section{Discussion}

The results of Experiment 2 demonstrate that the strength of metacontrast masking is reduced when the observer's attention is shifted to the target location by a spatial cue. This result suggests that the spatial and temporal parameters of the target and mask are not the only critical factors in metacontrast masking; attention may also play a role. The spatial and temporal parameters (8-item display, 80-msec SOA) that yielded robust masking in Experiment 1 were unchanged in Experiment 2, whereas the mask was rendered less effective by the attentional focusing caused by the cue. Thus, focusing one's attention on the target location prior to the target's onset is qualitatively similar to reducing the set size. Furthermore, the reduction in masking strength with an uninformative cue and only $50 \mathrm{msec}$ of cue lead time indicates that voluntary orienting of attention is not necessary to reduce metacontrast masking; a rapid and automatic orienting of attention is sufficient. Interestingly, valid cues did not cause performance to return to $100 \%$, as might have been anticipated. It is possible that valid but noninformative cues do not lead to the degree of focused attention that is possible when only a single item appears (set size $=1$ ). It is also possible, although unlikely, that the cue itself interfered slightly with the perceptibility of the subsequent target (forward masking).

It was expected that masking would be more pronounced on trials in which attention was directed to a distractor rather than to the target. Interestingly, no such deficit was associated with an invalid cue. It is perhaps incorrect to assume that, in the absence of a cue, attention is divided equally across the entire display in a diffuse manner. It may be that observers naturally attend to a specific location in the display at random in the moments preceding the onset of the target. An invalid cue might simply redirect this focusing of attention, but not to the location of the target. The absence of a decrement in performance with an invalid cue, as was found by Breitmeyer et al. (2000), suggests that voluntary and involuntary attention affect metacontrast masking in different ways. If so, this result is of theoretical importance because any successful theory accounting for the role of attention in metacontrast will need to differentiate between these two modes of orienting. 


\section{EXPERIMENT 3 \\ Masking is Reduced by Target Pop-Out}

In Experiment 2, a spatial cue was employed in order to direct attention to the location of the target. Another common manipulation that allows for rapid focusing of attention involves the similarity between the target and the distractors. Finding and focusing one's attention on a target bearing a high degree of similarity to distractors requires an inefficient search (serial search). The time required for one to complete this type of search increases with the number of distractors. Conversely, a target that is very different from the distractors can be located more rapidly and is said to "pop out." In pop-out displays, a target can be found and attended to rapidly, regardless of the number of distractors (see Treisman \& Gelade, 1980, and Wolfe, Cave, \& Franzel, 1989, for discussions of serial vs. pop-out search).

The hypothesis that metacontrast masking occurs more strongly when the target is unattended predicts that masking in multielement displays should depend on whether or not the target is found by pop-out or by serial search. If the deployment of attention to the target location is delayed because a serial (non-pop-out) search is required, metacontrast masking should be strong because the mask is likely to appear before the target has been located. If the target can be located rapidly (i.e., pops out), despite the presence of distractors, masking should be reduced or eliminated. Although Di Lollo et al. (2000) reported little masking of a pop-out target in a common-onset display, no study has yet compared pop-out and serial search. Experiment 3 was designed to test this prediction by directly comparing masking strength in pop-out and serial-search displays.

\section{Method}

In order to attribute changes in masking strength to attentional factors in Experiments 1 and 2, it was critical that only the attentional state of the observer be manipulated and that the spatial and temporal characteristics of the target and mask remain constant. This requirement imposed significant constraints on the design of Experiment 3. It was necessary that the type of search (pop-out or non-pop-out) be manipulated by changing the target's relationship to the distractors without changing its relationship to the mask. To accomplish this, a well-known asymmetry in visual search was exploited, and the observers performed a detection rather than a discrimination task. It is known that visual search for a ring with a gap among complete rings (a $\mathrm{C}$ among Os) is highly efficient, whereas search for a complete ring among rings with gaps (an $\mathrm{O}$ among $\mathrm{Cs}$ ) is inefficient (Treisman \& Souther, 1985). Given this search asymmetry, a display was designed in which the type of search (pop-out vs. non-pop-out) was manipulated, whereas the local configuration of target and mask was left constant across the two conditions.

The observers viewed a display consisting of two sequential frames, as in the previous experiments (Figure 5). There were two conditions, pop-out and non-pop-out, that differed only in the shape of the distractors and in the instructions to the observer. In the pop-out condition, the observer's task was to detect the presence of a single $\mathrm{C}$ among seven Os. One half of the trials were catch trials, on which all eight items were Os. In the non-pop-out condition, the observer was instructed to detect the presence of an $\mathrm{O}$ among seven Cs. Again, one half of the trials were catch trials, on which all eight items were Cs. In both conditions, the Cs were identical to those in Experiments 1 and 2, and the Os were simply the same Cs with the gaps filled in. The target and distractors were positioned randomly around a notional circle, as in the previous experiments. Although

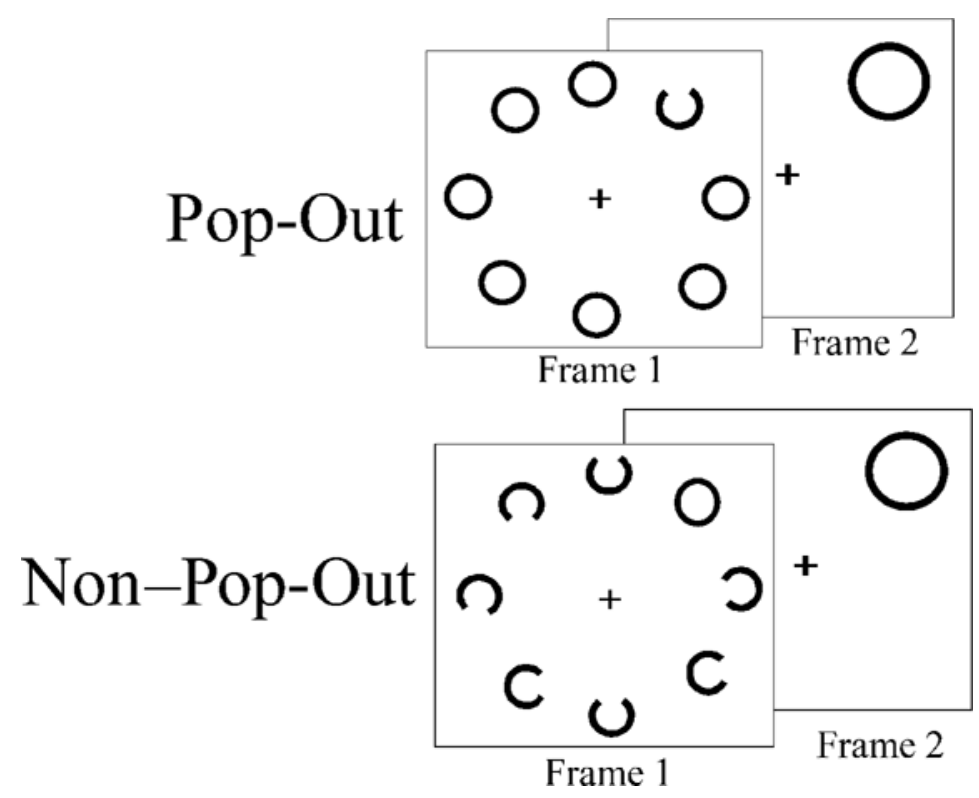

Figure 5. Schematic of the stimulus used in Experiment 3. Frame 1 contained a search array of a target and seven distractors. In separate blocks, the observers' task was to detect the presence of a $\mathrm{C}$ among Os (pop-out condition) or an $\mathrm{O}$ among $\mathrm{Cs}$ (non-pop-out condition). On catch trials, the array contained only distractors. A ring mask appeared at the target location in Frame 2 following a variable stimulus onset asynchrony. 
the orientation of the Cs was randomly up, down, left, or right, this was irrelevant to the task. The search array appeared in Frame 1 and vanished after $10 \mathrm{msec}$. Frame 2 was also displayed for $10 \mathrm{msec}$ and contained a single masking ring, as in Experiments 1 and 2. The mask appeared on every trial and always surrounded the target on target-present trials.

Two observers participated in Experiment 3, 1 of whom had participated in Experiments 1 and 2. Both observers viewed the displays in which the SOA was $0,20,40,80,120,160$, or $320 \mathrm{msec}$. Observer M.T. was also tested at SOAs of 380 and $420 \mathrm{msec}$ in the non-pop-out condition in order to obtain a more comprehensive masking function. This yielded a 2 (search type) $\times 7$ (SOA) design. Trials were blocked within conditions. Observer M.T. completed one block of 96 trials for each condition, and Observer T.H. completed three blocks of 96 trials for each condition.

\section{Results}

Simple analysis of accuracy on target-present trials is not appropriate here. In the non-pop-out condition, the target was a ring only slightly smaller than the mask, which was also a ring. If metacontrast masking was effective, the observers might have confused the visible mask with the invisible target, thus responding "yes" when the target was present (a hit) but also responding "yes" when it was absent (a false alarm). Likewise, in the pop-out condition, the observers would have been likely to confuse the visible mask with a distractor and respond "no" more frequently. Comparison of accuracy in the two conditions would not lead to conclusions based solely on the effectiveness of the mask. This situation was rectified by analyzing performance on both targetpresent and target-absent trials by using the techniques of signal detection theory. The similarity between the target and mask biases the observer toward more hits and more false alarms in the non-pop-out condition and toward fewer hits and fewer false alarms in the pop-out condition. The use of $d^{\prime}$ as a measure of sensitivity allows for the comparison between the two conditions because this measure is insensitive to changes in response bias. The $d^{\prime}$ measure was computed according to the procedure described by Macmillan and Creelman (1991).

Masking functions for both observers are presented in Figure 6. Performance in both the pop-out and non-popout conditions was near maximum at $\mathrm{SOA}=0$. In the popout condition, neither observer showed reliable evidence of masking. If anything, performance tended to increase with increasing SOA. The non-pop-out condition yielded very different results, with performance falling almost to chance at $\mathrm{SOA}=80$ for Observer T.H. and at SOA $=160$ for Observer M.T. A within-subjects ANOVA revealed a significant main effect of search type $[F(1,1)=561.075$, $\left.M S_{\mathrm{e}}=0.051, p=.03\right]$ and a significant interaction between search type and SOA $\left[F(6,6)=14.8445, M S_{\mathrm{e}}=\right.$ $0.098, p=.002]$. Masking in the non-pop-out condition also extended to long SOAs, with a depression of sensitivity still evident at $320 \mathrm{msec}$. For both observers, the mask became less effective at SOA $=320$. Only Observer M.T. was tested at SOAs long enough to show a complete rebound from masking. In this case, performance returned to the SOA $=0$ level by an SOA of $420 \mathrm{msec}$.

\section{Discussion}

The results of Experiment 3 strongly support the notion that the strength of metacontrast masking depends on selective attention to the target. The strength of metacontrast masking was modulated by changing the structural relationship between the target and the distractors, while keeping spatial and temporal parameters of the target and mask constant. This finding alone suggests that a local contour interaction between target and mask cannot be the only factor operating in metacontrast masking. More importantly, the functional difference between the two conditions was in the time course of shifting of attention to the target. In the non-pop-out condition, the observers were delayed in finding and focusing attention on the target, whereas in the pop-out condition, the tar-
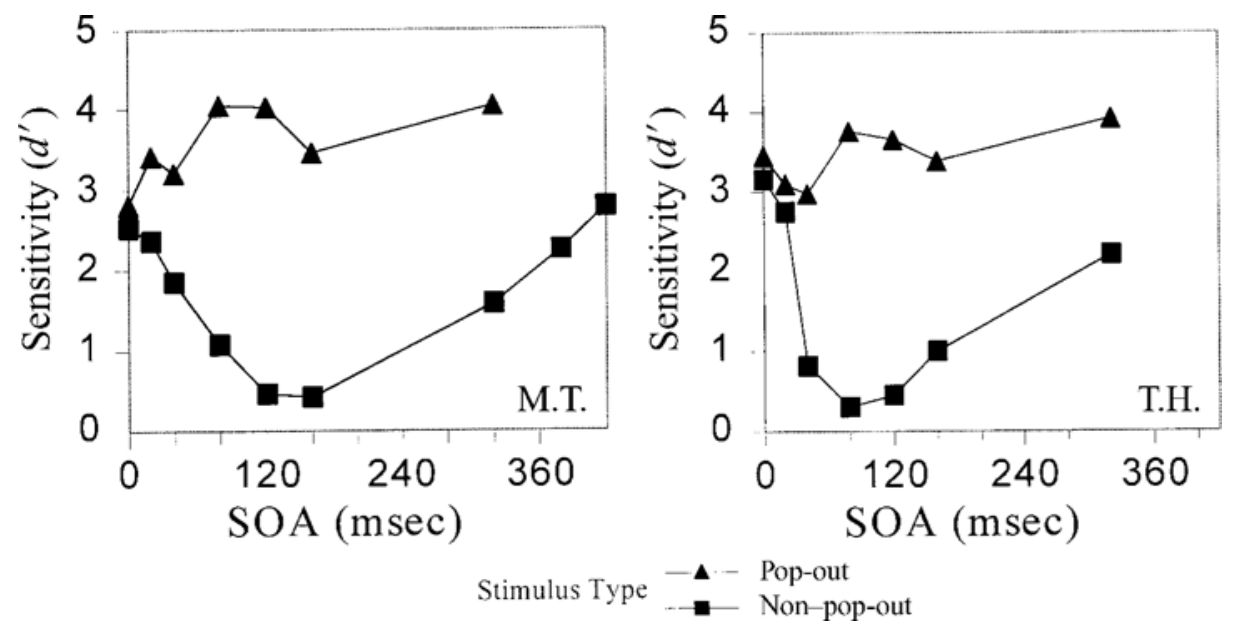

Figure 6. Results of Experiment 3 for 2 observers. Sensitivity $\left(d^{\prime}\right)$ in detecting the presence of the target as a function of stimulus onset asynchrony (SOA) in pop-out and non-pop-out conditions is plotted as a function of SOA. 
get was rapidly located and selectively attended. This difference in the dynamics of the observer's attention is responsible for the difference in the strength of masking. Metacontrast masking is stronger when the mask appears before attention has been focused on the target.

It is worth noting that masking in the non-pop-out condition was effective at SOAs substantially longer than those found in previous metacontrast masking studies. Masking is rarely, if ever, reported at target-mask SOAs in excess of $200 \mathrm{msec}$. Furthermore, transient-onsustained inhibition theories (e.g., Breitmeyer \& Ganz, 1976; Weisstein et al., 1975) fail to explain masking at such long SOAs. According to Breitmeyer and Ganz, interchannel inhibition should be maximal with SOAs of $50-100 \mathrm{msec}$. The pronounced masking still evident at SOAs far beyond this range suggests that this estimate does not apply to the masking of unattended targets.

The results of Experiment 3 also relate to the set-size effect demonstrated in Experiment 1. In Experiment 1, the target was singled out by a radial line extending toward it from the center of the display and by the subsequent appearance of the mask at the same location. This leaves open the possibility that the observed effect of set size resulted from the necessity of using an element of the display other than the target itself (either the line or the mask) to perform the task. In Experiment 3, this confound was eliminated since it was shown that a target, which could be located and reported without reference to other elements of the display, was still subject to strong metacontrast masking.

The phenomenological appearance of these displays is also worth contrasting with previous metacontrast masking studies. In metacontrast masking, visibility of the target is reduced, but its presence is nevertheless detectable (Fehrer \& Biederman, 1962). Furthermore, metacontrast display sequences are usually so brief that one has the sense that the target might have been missed rather than been rendered invisible. By contrast, masking in the non-pop-out condition was phenomenologically complete. With SOAs in the $100-300 \mathrm{msec}$ range, the observers reported seeing a blank space among the distractors where the target should have been.

\section{GENERAL DISCUSSION}

Metacontrast masking has long been conceptualized as involving low-level interactions between elements of a visual display acting over small distances. Although the precise mechanism by which the visual representation of the target becomes suppressed is unknown, the results of the present experiments strongly suggest that any theory based exclusively on low-level processes acting early in the visual system is insufficient. Visual selective attention clearly plays a role in the processes leading to backward masking of this type.

The role of attention has been explored in related masking paradigms involving different sequences and configurations of target and mask stimuli. Enns and Di Lollo (1997) used the term object substitution to describe the particularly strong masking that they found when the observer's attention was not focused at the target location. Di Lollo et al. (2000) went on to distinguish between two types of masking. One type, object substitution, is sensitive to attentional factors, such as set size and spatial cues, but is minimally sensitive to local spatial factors, such as contour proximity. The other is a low-level contour interaction process, which is sensitive to such factors as contour proximity and the level of dark adaptation of the observer, but it is not sensitive to attentional factors.

The backward masking observed in the present study has been referred to as metacontrast masking throughout this article. A major objective of the present work was to find out whether there exists a common susceptibility to attentional factors shared by both the classical metacontrast paradigm and the common-onset paradigm used by Di Lollo et al. (2000) to investigate object substitution. The present study demonstrates that attentional factors affect classical metacontrast masking and masking by common onset in similar ways. Should the robust masking observed in this study be called "metacontrast" or "object substitution"? The term metacontrast is often arbitrarily defined in regard to either the spatial relationship between target and mask (contours of a metacontrast mask do not overlap those of the target) or the temporal relationship between the stimuli (a metacontrast mask lags the target by some SOA and produces a U-shaped masking function). The term metacontrast masking has also become synonymous with the putative low-level contour interaction thought to underlie the phenomenon. The problem lies in the fact that strong backward masking can occur under conditions that are explicitly excluded by various definitions of metacontrast. Robust backward masking has been observed without an SOA (Di Lollo et al., 1993), with an excessively long SOA in Experiment 3 above, with a large spacing between target and mask (Di Lollo et al., 2000, and in the experiments above), and with a four-dot mask containing minimal contours (Enns \& Di Lollo, 1997). Indeed the complication was apparent as long ago as 1970, when Spencer and Shuntich reported that a low-energy mask with contours overlapping those of the target (arguably not a metacontrast mask) produced a U-shaped metacontrast-like masking function when distractors were included in the display.

The original use of the term metacontrast, or metaphotic contrast, by Stigler (1910; see Breitmeyer, 1984, chap. 1, for a historical review), in fact subsumes all these situations. Metaphotic contrast was meant to describe the interaction between the current (homophotic) percept of the mask and the lingering (metaphotic) percept of the recently vanished target. Thus, within Stigler's original definition, object substitution can be regarded as metacontrast masking, as can any low-level contour interaction 
that might also occur under the appropriate conditions. In the current literature (e.g., Di Lollo et al., 2000), however, the term object substitution has been used to denote masking that is sensitive to attentional factors, whereas the term metacontrast continues to denote masking that is low level, sensitive to local spatial factors, and independent of attention. Thus, despite having the spatial and temporal characteristics of classical metacontrast, the paradigm employed in the present study yielded masking that could be called object substitution rather than metacontrast.

The goal of this and previous studies has been to demonstrate that one's focusing attention on a target affects the strength of a subsequent mask. One of the questions that remains to be addressed in future investigations is "Does focusing attention on the mask also affect the strength of masking?" One possibility is that object substitution occurs when attention is focused on the mask during search for the target. Attention might be focused on the mask because its sudden onset (as in the present experiments) leads to attentional capture (see Yantis, 1996) or because it is, for a period of time, the only object in the display and is thus highly salient (as in the common-onset paradigm). One would predict then that factors that manipulate attentional selection of the mask should also modulate backward masking in complex displays. This prediction has been borne out by several initial experiments that have varied the salience of the mask (e.g., see Shelley-Tremblay \& Mack, 1999) and the set size and time of onset of several masks (e.g., see Tata \& Giaschi, 1999).

Recent electrophysiological studies have explored the neural correlates of selective attention in macaque visual areas V4 and IT. The results of these studies might be of considerable interest in future efforts to develop a "linking hypothesis" (Teller, 1990) that would explain the interaction between selective attention and masking in physiological terms. These studies have demonstrated that, in these areas, the initial activity of neurons responding to the onset of a target stimulus continues only if attention is directed to that stimulus. This neural activity is sharply suppressed, however, if attention is shifted to an adjacent (distractor) stimulus (Chellazi, Miller, Duncan, \& Desimone, 1993; Moran \& Desimone, 1985). The attentional selection of a target seems to preserve the neural representation of that target among these neurons, whereas the refocusing of attention on an adjacent stimulus suppresses the representation of the target among these neurons. That this behavior of neurons in macaque visual cortex might be a neural correlate of object substitution masking is an intriguing, albeit speculative, possibility.

The percept of a visual stimulus can be disrupted in a variety of ways. Object substitution, a variant of metacontrast masking, reflects the important influence of visual selective attention in mediating perception. As such, object substitution contributes to the emerging consensus, based on investigations of other related phenomena, such as inattentional blindness (Mack \& Rock, 1998), change blindness (Rensink, O'Regan, \& Clark, 1997; Simons \& Levin, 1997), and the attentional blink (Raymond, Shapiro, \& Arnell, 1992), that visual representations of unattended stimuli are impoverished and tenuous at best. Explanation of these phenomena will require paradigms that bridge the gap between low-level vision and higher level cognitive functions, and that lend themselves to investigation of the precise neural mechanisms underlying attentional selection and visual awareness. The phenomena of metacontrast and object substitution masking might prove to be useful tools in filling this need because they represent a convergence of the studies of attention and spatial and temporal vision.

\section{REFERENCES}

Averbach, E., \& Coriell, A. S. (1961). Short-term memory in vision. Bell System Technical Journal, 40, 309-328.

Breitmeyer, B. G. (1984). Visual masking: An integrative approach. New York: Oxford University Press.

Breitmeyer, B. [G.], Brown, V., Carter, M., \& Havig, P. (2000). Benefits and costs of attentional allocation in metacontrast. Abstracts of the Psychonomic Society, 5, 86-87.

BREITMEYER, B. G., \& GANZ, L. (1976). Implications of sustained and transient channels for theories of visual pattern masking, saccadic suppression, and information processing. Psychological Review, 83, 1-36.

Chellazi, L., Miller, E. K., Duncan, J., \& Desimone, R. (1993). A neural basis for visual search in inferior temporal cortex. Nature, 363, 345-347.

Di Lollo, V., Bischof, W. F., \& Dixon, P. (1993). Stimulus-onset asynchrony is not necessary for motion perception or metacontrast masking. Psychological Science, 4, 260-263.

Di Lollo, V., Enns, J. T., \& Rensink, R. A. (2000). Competition for consciousness among visual events: Psychophysics of reentrant pathways. Journal of Experimental Psychology: General, 129, 481-507.

Enns, J. T., \& Di Lollo, V. (1997). Object substitution: A new form of masking in unattended visual locations. Psychological Science, 8, 135-139.

Eriksen, C. W., \& Rohrbaugh, J. W. (1970a). Some factors determining efficiency of selective attention. American Journal of Psychology, 83, 330-342.

Eriksen, C. W., \& Rohrbaugh, J. W. (1970b). Visual masking in multielement displays. Journal of Experimental Psychology, 83, 147-154.

Fehrer, E., \& Biederman, I. (1962). A comparison of reaction and verbal report in the detection of masked stimuli. Journal of Experimental Psychology, 64, 126-130.

Finley, G. (1985). A high-speed point plotter for vision research. Vision Research, 25, 1993-1997.

MACK, A., \& Rock, I. (1998). Inattentionalblindness. Cambridge, MA: MIT Press.

Macmillan, N. A., \& Creelman, C. D. (1991). Detection theory: A user's guide. New York: Cambridge University Press.

Michaels, C. F., \& Turvey, M. T. (1979). Central sources of visual masking: Indexing structures supporting seeing at a single, brief glance. Psychological Research, 41, 1-61.

Moran, J., \& Desimone, R. (1985). Selective attention gates visual processing in the extrastriate cortex. Science, 229, 782-784.

Nakayama, K., \& Mackeben, M. (1989). Sustained and transient components of focal visual attention. Vision Research, 29, 1631-1647.

Posner, M. I., \& Cohen, Y. (1984). Components of visual orienting. In H. Bouma \& D. G. Bouwhuis (Eds.), Attention and performance X: Control of language processes (pp. 531-556). Hillsdale, NJ: Erlbaum.

RAMACHANDRAN, V. I., \& CoBB, S. (1995). Visual attention modulates metacontrast masking. Nature, 373, 66-68.

Raymond, J. E., Shapiro, K. S., \& Arnell, K. M. (1992). Temporary suppression in visual processing in an RSVP task: An attentional blink effect. Journal of Experimental Psychology: Human Perception \& Performance, 21, 653-662. 
Rensink, R. A., O’Regan, J. K., \& Clark, J. J. (1997). To see or not to see: The need for attention to perceive changes in scenes. Psychological Science, 8, 368-373.

Shelley-Tremblay, J., \& MACK, A. (1999). Metacontrast masking and attention. Psychological Science, 10, 508-515.

Simons, D. J., \& Levin, D. T. (1997). Change blindness. Trends in Cognitive Sciences, 1, 261-267.

Spencer, T. J., \& Shuntich, R. (1970). Evidence for an interruption theory of backward masking. Journal of Experimental Psychology, 85, 198-203.

Stigler, R. (1910). Chronophotische Studien über den Umgebungskontrast. Pflügers Archiv für die Gesamte Physiologie des Menschen und der Tiere, 135, 365-435.

TATA, M., \& Giaschi, D. (1999). Selective attention to the mask modulates object substitution masking. Investigative Ophthalmology \& Visual Science, 40, S806.

Teller, D. (1990). The domain of visual science. In L. Spillmann \& J. S. Werner (Eds.), Visual perception: The neurophysiologicalfoundations (Vol. 10, pp. 11-21). New York: Academic Press.

Treisman, A. M., \& Gelade, G. (1980). A feature integration theory of attention. Cognitive Psychology, 12, 97-136.
Treisman, A. M., \& Souther, J. (1985). Search asymmetry: A diagnostic for preattentive processing of separable features. Journal of Experimental Psychology: General, 114, 285-310.

UtTaL, W. R. (1970). On the physiological basis of masking with dotted visual noise. Perception \& Psychophysics, 7, 321-327.

Weisstein, N., Ozog, G., \& Szoc, R (1975). A comparison and elaboration of two models of metacontrast. Psychological Review, 82, 325-343.

Wolfe, J. M., Cave, K. R., \& Franzel, S. L. (1989). Guided search: An alternative to the feature integration model for visual search. Journal of Experimental Psychology: Human Perception \& Performance, 15, 414-433.

YANTIS, S. (1996). Attentional capture in vision. In A. F. Kramer, M. G. H. Coles, \& G. D. Logan (Eds.), Converging operations in the study of visual selective attention (pp. 45-76). Washington, DC: American Psychological Association.

(Manuscript received December 31, 2000; revision accepted for publication February 20, 2002.) 